\title{
DIREITOS HUMANOS E FUNDAMENTAIS: QUESTÕES CONCEITUAIS
}

Tanto na expressão "Direitos Humanos" quanto na expressão "Direitos Fundamentais" a palavra "direito" aparece em seu aspecto subjetivo, ou seja, ela denota um direito de um sujeito ou de um grupo de sujeitos e não uma norma ou um conjunto de normas de ação (direito objetivo). Direitos Humanos e Direitos Fundamentais são portanto direitos subjetivos, direitos que determinadas pessoas possuem. Mas são Direitos Humanos e Direitos Fundamentais sinônimos? Essa pergunta pode ser respondida de modos diferentes, sobretudo em razão de uma certa confusão na conceituação de Direitos Humanos e Fundamentais. A confusão começa com questões terminológicas, mas não se limita a elas, pois atinge também as características essências de ambos os conceitos. Assim, uma análise das questões conceituais referentes aos Direitos Humanos e Fundamentais deve abordar tanto questões terminológicas quanto questões conceituais propriamente ditas.

\section{Questões Terminológicas referentes a Direitos Humanos e Fundamentais}

Embora as expressões "Direitos Humanos" e "Direitos Fundamentais" sejam às vezes usadas como sinônimas, de modo geral se reconhece haver uma diferença entre elas. A primeira é geralmente relacionada a direitos pré-positivos, ou seja, direitos "morais", enquanto a segunda é geralmente relacionada a direitos positivos ou positivados, ou seja, "direitos jurídicos". Pode parecer estranho falar em um "direito moral", afinal de contas um "direito" (subjetivo) traz consigo implícita a ideia de pertinência ao Direito, do caráter "jurídico". Isso, porém, não é correto. A palavra direito, em seu sentido subjetivo, designa não só o correlato de um dever jurídico, mas também o correlato de um dever moral. Assim, se, por um lado, o credor afirma, diante do devedor, ter o "direito" de receber determinada quantia ou determinado bem (na medida em que o devedor tem o dever jurídico de pagar), por outro lado, também aquele que participa de uma discussão sobre um assunto sério afirma ter "direito" de exigir que seu interlocutor não minta (na medida em que o interlocutor tem o dever moral de não mentir). No segundo caso a palavra "direito" não é o correlato de um dever jurídico, mas antes de um dever moral. Curiosamente, esse segundo tipo de uso é consagrado na linguagem coloquial de diferentes tradições linguísticas como português, alemão e inglês, só para citar alguns exemplos. Mas não é só na linguagem coloquial que a palavra direito é empregada como correlato de um dever moral. Immanuel Kant afirma, em A Metafísica dos Costumes, que toda vez que

\footnotetext{
1 Doutor em Direito pela Universidade Federal de Minas Gerais (Estudos de Pós-Doutorado na Universidade de Saarland, na Universidade de Kiel e na Universidade de Heidelberg); Professor no Curso de Graduação em Direito e no Programa de Pós-graduação em Direito da Pontifícia Universidade Católica de Minas Gerais; Professor no Curso de Graduação em Direito e no Programa de Pós-graduação em Inovação Tecnológica e Propriedade Industrial da Universidade Federal de Minas Gerais; Avenida Pres. Antônio Carlos, 6627, Pampulha, 31270-901, Belo Horizonte, Minas Gerais, Brasil; https://orcid. org/00000002-9153-968X; a.travessoni@gmail.com
} 
há um dever, seja ele moral ou jurídico, há um direito a ele correspondente (Recht). Assim, quando se fala que Direitos Humanos são "direitos morais", quer-se dizer que eles são correlatos de deveres morais, e não de deveres jurídicos.

A terminologia alemã se refere aos direitos positivos ou positivados como Grundrechte (Direitos Fundamentais) e aos direitos pré-positivos (ou morais) como Menschenrechte (Direitos Humanos). Já a terminologia inglesa é mais complexa. Por um lado, a expressão inglesa Human Rights corresponde, em termos meramente terminológicos, à expressão alemã Menschenrechte, correspondendo assim ambas à expressão portuguesa Direitos Humanos. Porém, por outro lado, não é fácil encontrar um correspondente exato, na tradição inglesa, para a expressão alemã Grundrechte. Na tradição alemã, os Direitos Fundamentais são assim designados por estarem na Lei Fundamental, a Constituição da Alemanha (Grundgesetz). É claro que se pode argumentar serem eles designados dessa maneira não por estarem na Lei Fundamental, mas antes por serem direitos importantes, direitos que fundamentam outros direitos. Isso é em certa medida correto, mas não invalida a afirmação anterior, apenas complementando-a: por serem direitos muito importantes, os mais importantes, ou, em outros termos, por serem direitos que fundamentam outros direitos, eles devem estar positivados nas constituições, no caso da Alemanha a Lei Fundamental.

Qual seria, na língua inglesa, a expressão corresponde à expressão alemã Grundrechte, e consequentemente à expressão portuguesa "Direitos Fundamentais"? Há pelo menos quatro possibilidades: Fundamental Rights, Basic Rights, Constitutional Rights e Civil Rights. Enquanto as três primeiras possibilidades podem ser consideradas propostas "linguísticas", a quarta pode ser considerada uma proposta "cultural". Quando se emprega Fundamental Rights, Basic Rights ou Constitutional Rights como tradução da expressão portuguesa "Direitos Fundamentais" ou da expressão alemã Grundrechte, quer-se com isso enfatizar que esses direitos são direitos positivos que aparecem nas Constituições de um estado, que é sua lei fundamental. Por essa razão a palavra "fundamental(ais)" é traduzida por "fundamental", "basic" ou "constitutional". Por outro lado, quando se emprega a expressão Civil Rights, quer-se com isso conectar duas diferentes tradições jurídicas, que possuem histórias diferentes: a tradição da Europa continental e a tradição Norte-Americana. Nesta última, a ideia de que os direitos mais essenciais das pessoas devem ser reconhecidos pelo Estado foi fortemente influenciada pelo movimento dos direitos civis, que lutou pelo reconhecimento dos direitos sobretudo dos AfroAmericanos. Nesse contexto, distingue-se ainda Civil Rights de Civil Liberties, termo que se refere, em geral, às liberdades negativas no sentido clássico, ou seja, a limitações à interferência do Estado.

Uma questão terminológica importante resulta do caráter "fundamental" dos Direitos Humanos e do caráter "humano" dos Direitos Fundamentais. Como veremos abaixo, Direitos Humanos não protegem todo e qualquer bem social, mas apenas os bens sociais mais importantes, ou seja, os bens sociais essenciais ou fundamentais. Nessa medida, Direitos Humanos, ou seja, direitos pré-positivos que os seres humanos possuem, são direitos "fundamentais". Porém, precisa ficar claro que quando se afirma serem os Direitos Humanos direitos fundamentais, a palavra "fundamentais" 
não significa que esses direitos são positivados na Lei Fundamental (na Constituição), como ocorre no caso da expressão "Direitos Fundamentais", mas antes que esses direitos são essenciais, básicos, ou seja, muito importantes: direitos que fundamentam outros direitos.

Por outro lado, Direitos Fundamentais são direitos humanos, porque são direitos atribuídos por um Estado a determinados seres humanos, podendo, porém, ser atribuídos também a pessoas jurídicas, quando possível.

Em síntese, a dualidade terminológica "Direitos Humanos" e "Direitos Fundamentais" não significa que "Direitos Humanos" não sejam direitos essenciais (fundamentais), mas antes que eles são direitos que independem de positivação em uma Constituição (Lei Fundamental). Por outro lado, Direitos Fundamentais são direitos cujos portadores são, principalmente, seres humanos.

Uma última questão terminológica relevante diz respeito ao emprego da expressão "Direitos Humanos" no plano do Direito Internacional. Na tradição do Direito Internacional moderno e contemporâneo, a expressão "Direitos Humanos" não designa direitos garantidos apenas moralmente, ou seja, direitos pré-positivos, mas antes direitos protegidos pela ordem jurídica internacional, sobretudo pelas declarações de Direito Internacional. Como deve essa questão ser tratada? Há, a meu ver, duas possibilidades.

A primeira possibilidade seria considerar que o Direito Internacional não "positiva" direitos do mesmo modo que as ordens estatais o fazem. Uma razão para essa posição seria a ausência de órgãos de coerção autônomos por parte da comunidade internacional, ou seja, a inexistência de um Estado mundial. Kelsen já havia ressaltado, desde o início de sua carreira, que o Direito Internacional é uma ordem primitiva, na medida em que a aplicação da sanção, a saber, a represália e a guerra, é feita pelas próprias partes, ou seja, pelos Estados (KELSEN, 1934, p. 131). De lá para cá surgiram mecanismos conjuntos de aplicação de sanção, mas, na essência, a eficácia do Direito Internacional ainda depende, em grande medida, dos Estados individuais. Já que a expressão "Direitos Humanos" designa direitos pré-positivos, se o Direito Internacional não for considerado uma ordem jurídica capaz de positivar direitos seria coerente denominar os direitos previstos pela ordem internacional como "Direitos Humanos".

A segunda possibilidade é considerar que o Direito Internacional é uma ordem positiva ou, melhor dizendo, uma ordem capaz de positivar direitos. Assim sendo, quando uma declaração internacional de direitos surge, direitos pré-positivos ("Direitos Humanos" no sentido moral) tornam-se direitos positivos ou positivados. Considerando isso, três opções se mostram possíveis. A primeira opção seria combinar a ideia de que o Direito Internacional é capaz de positivar direitos com a dualidade terminológica "Direitos Humanos/Direitos Fundamentais" expressada acima. De acordo com essa opção, quando uma fonte do Direito Internacional protege um direito, esse direito se tornaria um Direito Fundamental. Essa solução, embora teoricamente possível, implicaria dois problemas. O primeiro deles seria não corresponder à terminologia de fato empregada no âmbito do Direito Internacional, enquanto o segundo problema seria não distinguir os direitos positivados por 
ordens jurídicas estatais dos direitos positivados pelo Direito Internacional. Poder-se-ia argumentar que a adição de um termo à expressão "Direitos Fundamentais", qualificando-a, resolveria o segundo problema. Isso de fato é verdade; poder-se-1́a empregar por exemplo a expressão "Direitos Fundamentais Internacionais". ${ }^{2}$ Porém, o primeiro problema permaneceria e, em virtude disso, essa solução deve ser abandonada.

A segunda opção seria criar um termo novo para designar um dos conceitos designados pela expressão "Direitos Humanos", reservando a própria expressão "Direitos Humanos" apenas para o conceito remanescente. Essa solução seria, porém, artificial, pois não corresponderia à prática da comunidade filosófica que se dedica aos Direitos Humanos ou à prática da comunidade Internacional, devendo por isso ser evitada.

Resta, portanto, uma terceira opção, que de fato parece ser a mais viável: adicionar um termo à expressão "Direitos Humanos", de modo que o problema existente, a saber, o fato de uma única expressão ("Direitos Humanos") designar dois conceitos, a saber os direitos pré-positivos essenciais dos seres humanos e os direitos essenciais dos seres humanos garantidos pela ordem jurídica internacional, desapareça. De acordo com essa solução, que de fato vem sendo adotada por alguns, a expressão "Direitos Humanos Internacionais" designa os direitos positivados pela ordem jurídica internacional (ALSTON; GOODMAN, 2012), enquanto a expressão "Direitos Humanos" designa os direitos pré-positivos que todos os seres humanos possuem.

Em síntese, há um problema terminológico que consiste na existência de três conceitos e apenas duas expressões para designar esses conceitos. Os conceitos são (a) direitos morais ou pré-positivos, (b) direitos positivados pelas ordens jurídicas dos estados e (c) direitos positivados pela ordem jurídica internacional. As duas expressões são (1) "Direitos Humanos" e (2) "Direitos Fundamentais". (1) pode designar (a) e (c), enquanto (2) designa (b). Mas com isso gera confusão, adiciona-se um qualificados à expressão 1, que passa a se desdobrar em (1.1) "Direitos Humanos" e (1.2) "Direitos Humanos Internacionais". De acordo com essa solução, que, a meu ver, é a mais adequada, (1) designa (a), (1.2) designa (c) e (2) designa (b).

Há dois argumentos fundamentais a favor dessa opção. $\bigcirc$ primeiro é que corresponde à terminologia já usada por um número considerável de internacionalistas e, além disso, é mais fácil de ser aceita por aqueles que ainda não a utilizam, ou seja, por aqueles que se referem aos direitos previstos pela ordem jurídica internacional como "Direitos Humanos". O segundo é que faz sentido se referir tanto aos direitos pré-positivos quando aos direitos previstos pela ordem jurídica internacional como Direito Humanos (no segundo caso adicionando o adjetivo "internacionais") porque ambos envolvem um consenso universal, um consenso internacional, no caso dos primeiros um consenso sobre sua validade moral e no caso dos segundos um consenso sobre sua validade jurídica.

$\overline{2}$ Borowski (2018, p. 37) parece cogitar essa possibilidade, ao referir-se a esses direitos que aqui são denominados "Direitos Humanos Internacionais” como “Direitos Humanos' como Direitos Fundamentais Internacionais.” 
Por isso, de agora em diante, usarei "Direitos Humanos" para me referir aos direitos prépositivos (ou morais) essenciais válidos moralmente, "Direitos Fundamentais" para me referir aos direitos essências positivados pelas ordens jurídicas dos Estados, e que estão geralmente em suas Constituições, e "Direitos Humanos Internacionais" para me referir aos direitos essenciais dos seres humanos que foram positivados pelo Direito Internacional.

\section{Os Conceitos de Direitos Humanos e Direitos Fundamentais}

O exame das questões terminológicas, realizado acima, já abordou a questão da delimitação de uma característica dos Direitos Humanos e Fundamentais: a validade moral ou jurídica. Agora, outras características devem ser analisadas. Para comparar as características essenciais dos Direitos Humanos e dos Direitos Fundamentais usarei a concepção de Robert Alexy sobre ambos.

No ensaio Direitos Humanos sem Metafísica? (ALEXY, 2014b, p. 99-112; ALEXY, 2004, p. 15-24), publicado originalmente em alemão, em 2004, Alexy aborda o conceito e a fundamentação dos Direitos Humanos. Aqui serão consideradas apenas suas observações referentes ao conceito de Direito Humanos. Para Alexy, Direitos Humanos são definidos através de cinco características. Eles são direitos (a) universais, (b) fundamentais, (c) abstratos, (d) morais ou pré-positivos e possuem (e) prioridade sobre outros direitos (ALEXY, 2014b, p. 100; ALEXY, 2004, p. 16).

A universalidade (a) dos Direitos Humanos significa que todos os seres humanos, enquanto seres humanos, os possuem. Enquanto a questão dos portadores ou titulares dos Direitos Humanos é relativamente pacífica, a questão sobre quem possui os deveres correlatos aos Direitos Humanos é, segundo Alexy, mais polêmica. Para ele, alguns Direitos Humanos podem ser contrapostos às pessoas que podem em geral possuir deveres, como seres humanos, estados e organizações internacionais, enquanto outros Direitos Humanos, como, por exemplo, os Direitos Políticos, podem ser contrapostos apenas em relação a Estados (ALEXY, 2014b, p. 100; ALEXY, 2004, p. 16).

O caráter fundamental (b) dos Direitos Humanos diz respeito, segundo Alexy, ao fato de que os objetos por eles protegidos não são todas as fontes e condições do bem estar dos seres humanos, mas antes apenas interesses e necessidades fundamentais(ALEXY, 2014b, p. 100; ALEXY, 2004, p. 16).

A terceira característica, o caráter abstrato dos Direitos Humanos (c), também diz respeito ao objeto de sua proteção. Para Alexy, pode-se facilmente reconhecer que todo ser humano possui um Direito Humano à saúde, mas não é tão fácil determinar, em um caso concreto, o que exatamente esse direito significa (ALEXY, 2014b, p. 100; ALEXY, 2004, p. 16).

A terceira e quarta características não dizem respeito, segundo Alexy, nem aos portadores e nem aos objetos da proteção, mas antes à validade dos Direitos Humanos (ALEXY, 2014b, p. 101; ALEXY, 2004, p. 16). A quarta característica é que a validade dos Direitos Humanos é meramente moral (d), o que já foi abordado acima. Deve-se, aqui, apenas adicionar que, para Alexy, a validade de um 
direito é sua existência, e a existência dos Direitos Humanos consiste em sua "fundamentabilidade", ou seja, na possibilidade de se poder fundamentá-los em um discurso moral (ALEXY, 2014b, p. 101; ALEXY, 2004, p. 16). Alexy reconhece que à validade moral adiciona-se a validade jurídica, quando um Direito Humano se transforma em direito positivo, ou seja, quando ele é positivado (ALEXY, 2014b, p. 101; ALEXY, 2004, p. 16).

A quinta característica é a prioridade (d). Direitos Humanos, como direitos moralmente válidos, não podem ser derrogados pelo direito positivo, ou seja, eles não perdem sua validade moral mesmo diante de um direito positivo a eles contrário, pois, na verdade, eles servem de padrão para a produção e a interpretação do direito positivo (ALEXY, 2014b, p. 101; ALEXY, 2004, p. 16).

No ensaio Direitos Fundamentais no Estado Democrático Constitucional (ALEXY, 2014a, p. 113129; ALEXY, 1997, p. 27-42), publicado originalmente em alemão, em 1997, Alexy aborda a posição dos Direitos Fundamentais no sistema jurídico (ALEXY, 2014a, p. 114-115; ALEXY, 1997, p. 28). Para ele, embora esse tipo de abordagem não constitua propriamente uma definição dos Direitos Fundamentais, ela contém elementos de uma tal definição. Segundo Alexy, Direitos Fundamentais são caracterizados por quatro "extremos". Eles são direitos que possuem (a') o grau mais elevado, (b') o maior potencial executório, (c') os conteúdos mais importantes e (d') a maior abertura (ALEXY, 2014a, p. 115; ALEXY, 1997, p. 28). Dentro do sistema jurídico.

Alexy afirma que o grau mais elevado (a') significa que os Direitos Fundamentais estão previstos nas Constituições. O maior potencial executório ( $b^{\prime}$ ) significa que eles são direitos que vinculam imediatamente os poderes legislativo, executivo e judiciário. Possuir os conteúdos mais importantes $\left(c^{\prime}\right)$ significa tratar de matérias que dizem respeito à estrutura fundamental da sociedade. Por fim, a maior medida de abertura (d') significa que eles são indeterminados (ALEXY, 2014a, p. 115-119; ALEXY, 1997, p. 28-29).

Agora que dispomos das caracterizações de Alexy tanto dos Direitos Humanos quanto dos Direitos Fundamentais, podemos compará-las.

Comecemos com a universalidade. Como vimos, Direitos Humanos são, enquanto direitos morais, universais. E os Direitos Fundamentais? Alexy não menciona a universalidade como uma de suas características, mas naturalmente ele os considera, em certo sentido, universais. A meu ver, por serem direitos previstos por Estados, Direitos Fundamentais não valem para todos os seres humanos. Sua validade está restrita aos âmbitos de validade das ordens jurídicas estatais que os prescrevem.

Com observa Kelsen (1934, p. 7-9), uma norma e consequentemente uma ordem jurídica válida possuem quatro diferentes âmbitos de validade: pessoal, material, espacial e temporal. Isso significa que uma norma e uma ordem válidas são válidas para certas pessoas, regulamentando certas matérias, em determinado espaço e em determinado momento. Quando se considera os âmbitos espacial e pessoal de validade da ordem jurídica estatal, pode-se dizer que Direitos Fundamentais são direitos em geral universais dentro do território do Estado, ou seja, eles valem, em geral, para todos os seres humanos que se encontram no âmbito espacial de validade da ordem jurídica do referido 
Estado. Mas algumas exceções podem ser feitas em relação ao âmbito pessoal. Podem ocorrer casos em que o Estado não atribui os mesmos direitos a seus cidadãos e a cidadãos estrangeiros que nele residam, e podem ocorrer casos em que o Estado atribua direitos a seus cidadãos, mesmo estando eles no território de outro estado.

Antes de continuarmos a comparação entre as características dos Direitos Humanos e dos Direitos Fundamentais deve ser feita uma última observação sobre a titularidade dos Direitos Fundamentais. Diferentemente de Direitos Humanos, cujos portadores são sempre seres humanos, Direitos Fundamentais podem ser atribuídos, por analogia, a pessoas jurídicas, quanto isso for possível.

Continuando a comparação, passemos à segunda característica dos Direitos Humanos, o caráter fundamental (b) dos objetos de sua proteção. Como vimos, na visão de Alexy os Direitos Humanos não protegem todos interesses e necessidades, mas apenas as mais essenciais ou fundamentais. Os Direitos Fundamentais também possuem essa característica? Se tomarmos os quatro extremos que Alexy atribui aos Direitos Fundamentais, podemos perceber que o fato de eles possuírem os conteúdos mais importantes (c') é a característica que mais se assemelha ao caráter fundamental dos Direitos Humanos, pois necessidades e interesses fundamentais são aqueles sem cuja efetividade os seres humanos não podem viver, são as necessidades e interesses mais importantes dos seres humanos.

A terceira característica dos Direitos Humanos é, como vimos, seu caráter abstrato (c). Assim como Direitos Humanos, Direitos Fundamentais também são direitos abstratos, pois eles não regulamentam detalhadamente as ações e omissões que devem ser praticadas nos casos concretos em que são aplicados. Na caracterização dos Direitos Fundamentais realizada por Alexy, isso se expressa através da "maior abertura" dos Direitos Fundamentais (d'). Essa característica, que a meu ver é uma das mais importantes tanto dos Direitos Humanos quanto dos Direitos Fundamentais, gera questões muitos interessantes, que não podem ser exploradas aqui, mas que podem pelo menos ser mencionadas, através de um exemplo. Parece razoável considerar o direito ao trabalho um Direito Humano, ou seja, um direito moral, pré-positivo, que todos os seres humanos possuem enquanto seres humanos. Esse Direito Humano encontra-se positivado no plano do direito de vários Estados, ou seja, em suas Constituições. Assim, por exemplo, a Constituição brasileira, em seu artigo $6^{\circ}$, determina que "são direitos sociais a educação, a saúde, a alimentação, o trabalho, a moradia, o transporte, o lazer, a segurança, a previdência social, a proteção à maternidade e à infância, a assistência aos desamparados, na forma desta Constituição." (BRASIL, 1988). Logo a seguir, nos trinta e quatro incisos do artigo $7^{\circ}$, a Constituição determina quais são os direitos individuais dos trabalhadores. Dentre eles está, por exemplo, a previsão da jornada de trabalho que, de acordo com o inciso XIII, não poderá ser "superior a oito horas diárias e quarenta e quatro semanais, facultada a compensação de horários e a redução da jornada, mediante acordo ou convenção coletiva de trabalho." (BRASIL, 1988). Percebe-se, portanto, que ao Direito Humano (pré-positivo, moral) ao Trabalho corresponde um Direito Fundamental (no exemplo acima, no Brasil) ao trabalho. Por outro 
lado, o direito do trabalhador "normal" de trabalhar não mais que oito horas por dia e quarenta e quatro horas por semana não é um direito tão indeterminado como o direito ao trabalho, mas antes bem mais específico que ele. As questões que devem ser postas, e que não pode ser respondida aqui, são as seguintes: o direito à jornada máxima de trabalho é um Direito Fundamental mesmo não sendo tão abstrato (ou aberto) quanto, por exemplo, o direito ao trabalho? Se afirmativo, existe um Direito Humano (moral, pré-positivo) a ele correspondente, ou seja, um Direito Humano de não trabalhar mais que determinado número de horas por dia ou semana? Em outros termos, a todo Direito Fundamental deve necessariamente corresponder um Direito Humano (moral pré-positivo)? Feitas essas observações e essas questões fundamentais, posso agora retomar a comparação entre os Direitos Humanos e os Direitos Fundamentais.

A quarta característica dos Direitos Humanos é que eles são direitos morais. À validade moral dos Direitos Humanos corresponde a validade jurídica dos Direitos Fundamentais, o que constitui, como já vimos, uma distinção essencial. Isso não significa que Direitos Humanos, quando positivados, transformando-se em Direitos Fundamentais, deixem de ser moralmente válidos. Como já ressaltado, com a positivação, à validade moral dos Direitos Humanos se adiciona a validade jurídica dos Direitos Fundamentais

À quinta e última característica dos Direitos Fundamentais, seu caráter prioritário (e), correspondem, a meu ver, o "grau mais elevado" dos Direitos Fundamentais na ordem jurídica dos Estados ( $\left.a^{\prime}\right)$ e seu maior potencial executório ( $\left.b^{\prime}\right)$; ou seja: eles estão na Constituição exatamente porque têm prioridade sobre outros direitos e para que todos os poderes do estado bem como todas as pessoas, sejam elas naturais (seres humanos) ou jurídicas sejam a eles vinculados.

Na verdade, o grau mais elevado dos Direitos Fundamentais ( $\left.a^{\prime}\right)$, o fato de eles protegerem os conteúdos mais importantes (c') e o seu maior potencial executório (b') parecem estar relacionados entre si. Os Direitos Fundamentais de fato estão no lugar mais elevado do sistema jurídico estatal (a Constituição) porque eles protegem os bens sociais mais importantes para os seres humanos, e para que eles tenham o poder de vincular todos os poderes do Estado e todas as demais pessoas, sejam elas pessoas naturais (seres humanos) ou jurídicas.

A comparação realizada acima pode ser resumida, portanto, do seguinte modo:

\begin{tabular}{|l|l|}
\hline Direitos Humanos & Direitos Fundamentais \\
\hline $\begin{array}{l}\text { universalidade moral ou ideal - válidos para todos os seres } \\
\text { humanos }\end{array}$ & $\begin{array}{l}\text { universalidade relativa - limitada aos âmbitos pessoal e } \\
\text { espacial de validade da ordem jurídica estatal }\end{array}$ \\
\hline caráter fundamental & conteúdos mais importantes \\
\hline caráter abstrato & maior abertura \\
\hline validade moral & validade jurídica \\
\hline prioridade & $\begin{array}{l}\text { o grau mais elevado nas ordens estatal e o maior potencial } \\
\text { executório }\end{array}$ \\
\hline
\end{tabular}


Agora, os Direitos Humanos Internacionais devem ser adicionados a essa comparação. Como já ressaltei, Direitos Humanos Internacionais são Direitos previstos pela ordem jurídica internacional. À universalidade dos Diretos Humanos (a), à qual, como vimos, corresponde uma universalidade meramente relativa dos Direitos Fundamentais, corresponde, em princípio, uma universalidade muito mais ampla dos Direitos Humanos Internacionais, que decorre do fato de eles serem válidos em todos os Estados que aderiram às declarações que os prescrevem. Mais ainda, para alguns teóricos, eles são válidos até mesmo nos Estados que não aderiram aos tratados ou a determinados tratados de Direito Internacional que os prescrevem. De todo modo, os âmbitos pessoal e espacial de validade da ordem jurídica internacional são consideravelmente mais amplos que os de qualquer ordem estatal.

Ao caráter fundamental dos Direitos Humanos (b) corresponde a maior importância dos interesses e necessidades protegidos pelos Direitos Humanos Internacionais. Naturalmente, aquilo que é considerado importante no plano de um Estado individual pode não ser considerado importante no plano do Direito Internacional, o que pode resultar em uma certa dissimetria entre Direitos Fundamentais e Direitos Humanos Internacionais. Assim, pode-se dizer que Direitos Fundamentais protegem interesses e necessidades no plano das sociedades que constituem os Estados nacionais, enquanto Direitos Humanos Internacionais protegem interesses e necessidades que são essenciais para todos os seres humanos.

Ao caráter abstrato dos Direitos Humanos (c) corresponde o caráter aberto ou abstrato dos Direitos Humanos Internacionais. Aqui, exatamente como já tinha sido o caso quando da comparação entre a abstração dos Direitos Humanos e a maior abertura dos Direitos Fundamentais, novamente coloca-se a questão sobre a correspondência entre a abstração de Direitos Humanos pré-positivos e de direitos positivados, mas especificamente os Direitos Humanos Internacionais. Para ilustrar essa questão, convém voltar ao exemplo já mencionado do direito ao trabalho e do direito a uma jornada máxima de trabalho. Como vimos acima, parece razoável considerar o direito ao trabalho um Direito Humano, ou seja, um direito moral, pré-positivo. Esse direito, além de estar positivado em ordenamentos jurídicos estatais, no caso do Brasil no artigo $6^{\circ}$ da Constituição (BRASIL, 1988), encontra-se também positivado, no plano do Direito Internacional, pela Declaração Universal dos Direitos Humanos (ORGANIZAÇÃO DAS NAÇÕES UNIDAS, 1948), que determina, em seu artigo 23 (1): "toda pessoa tem direito ao trabalho, à livre escolha do trabalho, a condições equitativas e satisfatórias de trabalho e à proteção contra o desemprego." Em relação à duração da jornada de trabalho, o Tratado de Versalhes já previa, em seu artigo 427, "a adoção de um padrão de oito horas por dia ou quarenta e oito horas por semana como padrão a ser perseguido onde ele ainda não tenha sido obtido." Cabe, aqui, repetir as perguntas feitas acima, trocando agora os Direitos Fundamentais

3 No original: "The adoption of an eight hours day or a forty-eight hours week as the standard to be aimed at where it has not already been attained." 
pelos Direitos Humanos Internacionais: o direito à jornada máxima de trabalho é um Direito Humano Internacional mesmo não sendo tão abstrato (ou aberto) quanto, por exemplo, o direito ao trabalho? Se afirmativo, existe um Direito Humano (moral, pré-positivo) a ele correspondente, ou seja, um Direito Humano de não trabalhar mais que determinado número de horas por dia ou semana? Em outros termos, a todo Direito Humano Internacional deve necessariamente corresponder um Direito Humano (moral pré-positivo)? A essas questões podem ser adicionadas ainda questões sobre a correspondência entre a abstração dos Direitos Humanos Internacionais e a abstração dos Direitos Fundamentais, que, contudo, não podem ser desenvolvidas aqui.

A quarta característica dos Direitos Humanos (d) é, como vimos, sua validade moral. A ela corresponde a validade jurídica dos Direitos Humanos Internacionais pois, como vimos acima, o Direito Internacional é Direito e, por isso, capaz de realizar a tarefa de positivação.

À quinta característica dos Direitos Humanos, sua prioridade (e), corresponde o caráter prioritário dos Direitos Humanos Internacionais dentro da ordem jurídica internacional, o que não é possível porém desenvolver com mais detalhes aqui.

Assim, a correspondência final entre Direitos Humanos, Direitos Fundamentais e Direitos Humanos Internacionais pode ser exposta da seguinte forma:

\begin{tabular}{|l|l|l|}
\hline Direitos Humanos & Direitos Fundamentais & Direitos Humanos Internacionais \\
\hline $\begin{array}{l}\text { universalidade moral ou ideal - válidos } \\
\text { para todos os seres humanos }\end{array}$ & $\begin{array}{l}\text { universalidade relativa - limitada aos } \\
\text { ambitos pessoal e espacial de validade } \\
\text { da ordem jurídica estatal }\end{array}$ & $\begin{array}{l}\text { universalidade jurídica - válidos para } \\
\text { todos os seres humanos (aplicabilidade } \\
\text { do Direito Internacional }\end{array}$ \\
\hline caráter fundamental & conteúdos mais importantes & conteúdos mais importantes \\
\hline caráter abstrato & maior abertura & maior abertura \\
\hline validade moral & $\begin{array}{l}\text { validade jurídica (no plano dos Estados } \\
\text { individuais) }\end{array}$ & $\begin{array}{l}\text { validade jurídica (no plano do Direito } \\
\text { Internacional) }\end{array}$ \\
\hline prioridade & $\begin{array}{l}\text { o grau mais elevado nas ordens } \\
\text { estatais e o maior potencial executório }\end{array}$ & $\begin{array}{l}\text { prioridade das normas de Direito } \\
\text { internacional que estabelecem Direitos } \\
\text { Humanos }\end{array}$ \\
\hline
\end{tabular}

Essa conclusão é singela e não resolve as inúmeras e complexas questões que se colocam na conceituação e fundamentação de Direitos Humanos, Direitos Fundamentais e Direitos Humanos Internacionais, bem como na aplicação dos segundos e dos terceiros. Mas como em toda matéria deve-se primeiramente abordar as questões básicas para então se abordar as questões complexas, a análise aqui realizada pode ter alguma utilidade.

\section{Referências}

ALEXY, Robert. Direitos Fundamentais no Estado Democrático Constitucional. In: TRIVISONNO, Alexandre T. G. (org.). Teoria Discursiva do Direito. 2. ed. Rio de Janeiro: Forense Universitária, 2014a. 
ALEXY, Robert. Direitos Humanos sem Metafísica? In: TRIVISONNO, Alexandre T. G. Teoria Discursiva do Direito. (org.). 2. ed. Rio de Janeiro: Forense Universitária, 2014b.

ALEXY, Robert. Grundrechte im demokratischen Verfassungsstaat. Justice, Morality and Society. A Tribute to Aleksander Peczenik on the Occasion of his 60th Birthday - 16 November 1997. Lund: Juristförlaget i Lund, 1997.

ALEXY, Robert. Menschenrechte ohne Metaphysik? Deutsche Zeitschrift für Philosophie, [S. l.], v. 1, p. 15-24, 2004.

ALSTON, Philip; GOODMAN, Ryan. International Human Rights. Oxford: Oxford University Press, 2012.

BOROWSKI, Martin. Grundrechte als Prinzipien. 3. Auflage. Tübingen: Mohr Siebeck, 2018.

BRASIL. Constituição: República Federativa do Brasil de 1988. Brasília, DF: Senado Federal, 1988.

KELSEN, Hans. Reine Rechtslehre. Leipzig und Wien: Franz Deuticke, 1934.

ORGANIZAÇÃO DAS NAÇÕES UNIDAS. Declaração Universal dos Direitos Humanos. 1948. Disponível em: https://nacoesunidas.org/wp-content/uploads/2018/10/DUDH.pdf. Acesso em: 20 maio 2020 . 
